\title{
Major determinants of circulating myostatin in polycystic ovary syndrome
}

\author{
HALDUN ARPACI \\ Department of Obstetrics and Gynecology, Kafkas University School of Medicine, Kars 36000, Turkey
}

Received June 16, 2018; Accepted November 16, 2018

DOI: $10.3892 /$ etm.2018.7080

\begin{abstract}
The present study was designed to investigate the possible impact of hormonal and demographic parameters of patients with polycystic ovary syndrome (PCOS) on the circulating levels of myostatin. The study cohort comprised 46 patients with PCOS and 42 healthy female controls, and all subjects were of normal weight. Multiple regression analysis was applied to investigate the possible associations between serum myostatin levels and other laboratory parameters. Evaluation of the levels of myostatin revealed no significant differences between the PCOS and control groups $(\mathrm{P}>0.05)$. In the control group, no significant correlations were identified between the myostatin levels and any other laboratory parameters. Only low-density-lipoprotein cholesterol (LDL-C) levels in the PCOS group were revealed to be significantly, although negatively, associated with myostatin levels $(\mathrm{P}=0.018)$. In the regression model of the PCOS group, an increase in LDL-C and prolactin (PRL) were associated with a decrease in myostatin ( $\mathrm{P}=0.001$ and $\mathrm{P}=0.013$, respectively). Furthermore, a decrease in sex hormone-binding globulin (SHBG), fasting blood glucose (FBG) and monocytes were associated with an increase in myostatin $(\mathrm{P}=0.028, \mathrm{P}<0.001$ and $\mathrm{P}=0.026$, respectively). An increase in triglycerides was also associated with an increase in myostatin $(\mathrm{P}=0.001)$. In the regression model of the control group, a decrease in LDL-C was associated with an increase in myostatin $(\mathrm{P}=0.003)$ and a decrease in thyroid-stimulating hormone was associated with a decrease in myostatin $(\mathrm{P}=0.028)$. These results indicated that the normal range of myostatin levels in patients with PCOS is regulated by changes in the circulating levels of PRL, LDL-C, SHBG, triglycerides, monocytes and FBG.
\end{abstract}

Correspondence to: Dr Haldun Arpaci, Department of Obstetrics and Gynecology, Kafkas University School of Medicine, 38 Turan Celik Street, Kars 36000, Turkey

E-mail:makabal@mynet.com

Key words: polycystic ovary syndrome, myostatin, insulin resistance, fasting blood glucose, low density lipoprotein cholesterol

\section{Introduction}

Polycystic ovary syndrome (PCOS) is characterized by three major clinical features: Oligo-ovulation/anovulation, clinical and/or biochemical hyperandrogenism and polycystic ovaries (1). Skeletal muscle and adipose tissue exert an important role in the regulation of metabolism in PCOS (2-4), and are responsible for the production of numerous peptides that are classified as myokines (5-7). Myostatin, also known as growth differentiation factor 8 , is a member of the transforming growth factor- $\beta$ superfamily (8). It is predominantly expressed in the skeleton, although it is also synthesized by adipose tissue and cardiomyocytes $(8,9)$. Myostatin is the major negative regulator of post-natal skeletal muscle growth via paracrine and endocrine functions $(10,11)$. It acts by binding to myostatin activin type II receptor (12). The essential function of myostatin is to regulate the general metabolic balance between fat and skeletal muscle in the body (13). In this context, it co-ordinates the associations between lipids, proteins, obesity and insulin resistance (IR) (14-17).

Over the last few years, there has been an increasing interest in investigating the functional roles of myostatin outside the musculoskeletal system. In this regard, it has been revealed that myostatin serves important roles in the pathogenesis of various gynecological diseases, including PCOS (18-20). However, to the best of our knowledge, only one study has previously been published that investigated the association between myostatin and PCOS. In that study, Chen et al (20) demonstrated that the level of myostatin was positively associated with abdominal obesity, although it was negatively associated with the circulating levels of dehydroepiandrosterone sulfate (DHEA-S) in women with PCOS.

The essential regulators of the serum levels of myostatin have not yet be to fully identified. Abdominal obesity (20), androgens (21) and skeletal muscle mass $(10,11)$ are the major components involved in myostatin synthesis and release. However, the mechanisms of the association between circulating insulin, glucose levels and serum myostatin have remained to be fully elucidated. Numerous studies have failed to explain the importance of the autocrine effects of myostatin on insulin sensitivity. Certain studies have revealed an association between serum myostatin levels and IR $(17,22,23)$, whereas others reported no significant association (24-26). Similarly, the association between the levels of blood glucose and muscle myostatin has not previously been clearly demonstrated. 
Therefore, the aim of the present study was to investigate the effects of hormonal levels and demographic features of PCOS patients on their serum myostatin levels.

\section{Patients and methods}

Subject enrollment and data collection. The study protocol was in accordance with the Declaration of Helsinki, and was approved by the Local Ethics Committee of Kafkas University School of Medicine. Written informed consent was obtained from all subjects included. The circulating myostatin levels were evaluated in the serum obtained during the early follicular phase from 46 normal-weight patients with PCOS, and from 42 control subjects without PCOS. Patients in the PCOS and control groups were matched in body mass index (BMI) value. The detailed history (including medical and family histories) of all of the patients was recorded and anthropometric data [age, body weight (in $\mathrm{kg}$ ), height (in $\mathrm{cm}$ ) and waist circumference (in $\mathrm{cm}$ )] were determined. The body height and weight of the patients were measured with the patient standing barefoot in light clothes. The BMI (in $\mathrm{kg} / \mathrm{m}^{2}$ ) was calculated according to the following formula: Body weight/body height ${ }^{2}$. The waist circumference was measured at the level halfway between the lower rib and the iliac crest. Participants in the PCOS group were diagnosed based on the revised Rotterdam criteria (1), which require the presence of two of the following three clinical manifestations: i) Oligo-ovulation and/or anovulation; ii) clinical and/or biochemical hyperandrogenism; and iii) polycystic ovaries determined by ultrasonography. The ultrasound criteria used for diagnosis of polycystic ovary were the presence of 12 or more follicles in each ovary measuring 2-9 $\mathrm{mm}$ in diameter, and/or an increased ovarian volume (>10 ml). Biochemical hyperandrogenism was defined as the total testosterone level being above the normal range of $0.34-2.60 \mathrm{nmol} / \mathrm{l}$. Clinical hyperandrogenism was determined as patients scoring at least 8 points according to the Ferriman-Gallwey hyperandrogenism scoring system (27). Women in the control group had regular menses and normal biochemical and hormonal profiles, thereby excluding PCOS. The women in the control group exhibited no evidence of hyperandrogenic manifestations or polycystic appearance upon ultrasonography of the ovaries. Menstrual periods were characterized by oligomenorrhea (absence of menstruation for $\geq 45$ days) or by amenorrhea (no menstrual period for $\geq 3$ months) in the PCOS group. Menstrual periods in the control group were regular, with a cycle of 25-32 days. None of the patients included in the present study received any therapeutic treatment for PCOS. The patients were also evaluated for physical activity. It was observed that the majority of patients did not engage in any regular sporting activity beyond daily routine. Smokers and subjects taking anti-androgens, anti-diabetics, insulin sensitizers, lipid-lowering medications, glucocorticoids or any type of hormonal drug were excluded from the study. All participants had normal renal and hepatic function test results. Patients were also excluded from the study if they were pregnant or lactating, or had hyperprolactinemia, Cushing's syndrome, congenital adrenal hyperplasia, thyroid disorders, impaired glucose tolerance, type 1 or type 2 diabetes mellitus or a history of ovarian surgery.
Laboratory analyses. Venous blood samples were taken from all participants for analysis of the hormonal status, lipid profile, fasting blood glucose (FBG) and insulin levels. The blood samples were taken in the morning following overnight fasting, at the second day of early follicular phase of spontaneous bleeding. The blood samples were centrifuged at $1,000 \mathrm{x} \mathrm{g}$ for $15 \mathrm{~min}$ at $2-8^{\circ} \mathrm{C}$, and aliquots of the serum obtained were subsequently stored at $-80^{\circ} \mathrm{C}$ until analysis. Serum myostatin concentrations were assessed using an Elabscience ${ }^{\circledR}$ ELISA (cat. no. E-EL-H1437; Elabscience Biotechnology Co., Ltd., Wuhan, China). The sensitivity of this test to serum myostatin was $0.47 \mathrm{ng} / \mathrm{ml}$ and the detection range was 0.78 to $50 \mathrm{ng} / \mathrm{ml}$. Furthermore, FBG, serum insulin, high-density-lipoprotein cholesterol (HDL-C), low-density-lipoprotein cholesterol (LDL-C), triglyceride, total cholesterol, follicle-stimulating hormone (FSH), luteinizing hormone $(\mathrm{LH})$, estradiol $\left(\mathrm{E}_{2}\right)$, prolactin (PRL), thyroid-stimulating hormone (TSH), total testosterone, DHEA-S, sex hormone-binding globulin (SHBG), high-sensitivity C-reactive protein (hs-CRP), albumin and the complete blood count (comprising neutrophils, lymphocytes, monocytes and platelets) were measured. FBG (cat. no. 3L82-21), hs-CRP (cat. no. 6K26-30), total cholesterol (cat. no. 7D62-21), HDL-C (cat. no. 3K33-20), LDL-C (cat. no. 1E31-20), and triglyceride (cat. no. 7D74-21) levels were determined using an Abbott Architect ${ }^{\mathrm{TM}} \mathrm{C} 16000$ automated analyzer (Abbott Pharmaceutical Co. Ltd., Lake Bluff, IL, USA) with kits provided by the manufacturer (Abbott Diagnostics GmbH, Wiesbaden, Germany). Serum FSH (cat. no. 33520), LH (cat. no. 33510), $\mathrm{E}_{2}$ (cat. no. 33540), insulin (cat. no. 33410), total testosterone (cat. no. 33560), PRL (cat. no. 33530), TSH (cat. no. 33820), SHBG (cat. no. A48617) and DHEA-S (cat. no. A10826) levels were measured via CMIA (Beckman Coulter Inc., Brea, CA, USA).

Fasting insulin levels were measured in the subjects of the PCOS and control groups in order to determine their insulin sensitivity. IR was calculated using the homeostasis model assessment IR index (HOMA-IR) according to the following formula: HOMA-IR=fasting serum insulin $(\mu \mathrm{IU} / \mathrm{ml}) \times \mathrm{FBG}$ $(\mathrm{mg} / \mathrm{dl}) / 405$ (28). The free androgen index (FAI) was calculated as $100 \mathrm{x}$ the total testosterone count $(\mathrm{nmol} / \mathrm{l}) / \mathrm{SHBG}(\mathrm{nmol} / \mathrm{l})$.

Statistical analysis. Data analyses were performed using SPSS version 24.0 (IBM Corp., Armonk, NY, USA). For assessing the data for being normally distributed, the Kolmogorov-Smirnov test was performed instead of the Shapiro-Wilk test, since the study sample was $>30$. With the exception of those variables that were not distributed normally, including PRL, LDL-C, total cholesterol, albumin, neutrophil, lymphocyte and platelets, the non-parametric Mann-Whitney U test was applied. As no significant differences were identified using analysis of variance with the Kruskal-Wallis test, no post-hoc test was performed. A student's t-test was used for parameters with normal distribution. Pearson correlation and the non-parametric Spearman correlation test were applied to examine the correlations between myostatin levels and clinical data of subjects with or without PCOS. Multiple regression analysis was applied to investigate the associations between myostatin levels and other parameters. Values are expressed as the mean \pm standard deviation. $\mathrm{P}<0.05$ was considered to indicate a statistically significant difference. 
Table I. Comparison of the demographic and laboratory characteristics of the patients.

\begin{tabular}{|c|c|c|c|c|c|}
\hline Parameter & Controls $(n=42)$ & $\begin{array}{l}\text { PCOS } \\
(n=46)\end{array}$ & $\begin{array}{l}\text { Whole population } \\
\qquad(\mathrm{n}=88)\end{array}$ & $\begin{array}{l}\text { Reference } \\
\text { ranges }^{\mathrm{a}}\end{array}$ & P-value ${ }^{b}$ \\
\hline Age (years) & $29.02 \pm 6.85$ & $24.89 \pm 6.11$ & $26.86 \pm 25.00$ & & $0.004^{\mathrm{b}}$ \\
\hline BMI $\left(\mathrm{kg} / \mathrm{m}^{2}\right)$ & $25.00 \pm 4.79$ & $25.34 \pm 5.54$ & $25.18 \pm 23.90$ & $18.50-24.90$ & 0.943 \\
\hline Waist circumference $(\mathrm{cm})$ & $77.29 \pm 10.87$ & $78.22 \pm 11.68$ & $77.77 \pm 77.00$ & $<80.00$ & 0.676 \\
\hline $\mathrm{FSH}(\mathrm{mIU} / \mathrm{ml})$ & $8.71 \pm 4.03$ & $6.93 \pm 1.58$ & $7.78 \pm 7.37$ & $3.85-8.78$ & $0.008^{b}$ \\
\hline LH (mIU/ml) & $5.13 \pm 2.16$ & $7.20 \pm 3.92$ & $6.21 \pm 5.48$ & $2.12-10.89$ & $0.010^{\mathrm{b}}$ \\
\hline Estradiol (pg/ml) & $81.63 \pm 56.94$ & $68.85 \pm 44.95$ & $74.95 \pm 60.00$ & $27.00-122.00$ & 0.356 \\
\hline Prolactin (ng/ml) & $12.15 \pm 6.87$ & $13.20 \pm 5.52$ & $12.70 \pm 11.73$ & $3.34-26.72$ & 0.429 \\
\hline $\mathrm{TSH}(\mu \mathrm{IU} / \mathrm{ml})$ & $1.80 \pm 0.92$ & $2.34 \pm 1.60$ & $2.08 \pm 1.79$ & $0.34-5.60$ & 0.172 \\
\hline HDL-C (mg/dl) & $57.20 \pm 11.96$ & $57.59 \pm 12.74$ & $57.40 \pm 56.0$ & $45.00-65.00$ & 0.904 \\
\hline LDL-C (mg/dl) & $93.31 \pm 25.70$ & $88.56 \pm 27.49$ & $90.83 \pm 92.10$ & $<130.00$ & 0.406 \\
\hline Triglyceride (mg/dl) & $123.38 \pm 61.83$ & $138.83 \pm 82.40$ & $131.45 \pm 108.00$ & $<200.00$ & 0.613 \\
\hline Total cholesterol (mg/dl) & $172.38 \pm 36.50$ & $173.91 \pm 30.45$ & $173.18 \pm 172.00$ & $<200.00$ & 0.831 \\
\hline DHEA-S $(\mu \mathrm{g} / \mathrm{dl})$ & $180.08 \pm 97.00$ & $218.26 \pm 109.00$ & $200.04 \pm 177.15$ & $23.00-266.00$ & 0.087 \\
\hline Total testosterone (nmol/l) & $1.53 \pm 0.69$ & $1.73 \pm 1.07$ & $1.64 \pm 1.51$ & $0.34-2.60$ & 0.722 \\
\hline SHBG $(n m o l / 1)$ & $63.58 \pm 24.39$ & $58.21 \pm 35.63$ & $60.77 \pm 56.70$ & $19.80-155.20$ & 0.070 \\
\hline FAI $(\%)$ & $2.75 \pm 1.86$ & $4.24 \pm 3.70$ & $3.53 \pm 2.69$ & $0.50-6.50$ & $0.038^{\mathrm{b}}$ \\
\hline FBG (mg/dl) & $91.48 \pm 9.55$ & $93.96 \pm 14.86$ & $92.77 \pm 92.00$ & $70.00-100.00$ & 0.403 \\
\hline Insulin $(\mu \mathrm{IU} / \mathrm{ml})$ & $11.76 \pm 10.65$ & $14.64 \pm 21.05$ & $13.27 \pm 8.54$ & $1.90-23.00$ & 0.056 \\
\hline HOMA-IR & $2.77 \pm 2.74$ & $4.00 \pm 8.25$ & $3.42 \pm 1.91$ & $<3.00$ & 0.072 \\
\hline Myostatin (ng/ml) & $28.27 \pm 35.48$ & $17.52 \pm 11.20$ & $22.65 \pm 15.93$ & $7.00-32.00$ & 0.475 \\
\hline hs-CRP (mg/l) & $0.20 \pm 0.20$ & $0.33 \pm 0.71$ & $0.27 \pm 0.14$ & $<0.50$ & 0.884 \\
\hline Albumin (g/dl) & $4.57 \pm 0.34$ & $4.48 \pm 0.30$ & $4.52 \pm 4.51$ & $3.50-5.20$ & 0.176 \\
\hline Neutrophils $\left(\times 10^{3} / \mu 1\right)$ & $3.91 \pm 1.02$ & $4.21 \pm 1.24$ & $4.07 \pm 3.99$ & $1.80-7.80$ & 0.219 \\
\hline Lymphocytes $\left(\mathrm{x} 10^{3} / \mu 1\right)$ & $1.89 \pm 0.50$ & $1.91 \pm 0.50$ & $1.90 \pm 1.90$ & $0.90-3.70$ & 0.808 \\
\hline Monocytes $\left(\times 10^{3} / \mu 1\right)$ & $0.40 \pm 0.15$ & $0.43 \pm 0.15$ & $0.42 \pm 0.38$ & $0.30-0.90$ & 0.318 \\
\hline Platelets $\left(\mathrm{x} 10^{3} / \mu 1\right)$ & $277.24 \pm 70.47$ & $277.07 \pm 61.44$ & $277.15 \pm 276.50$ & $149.00-371.00$ & 0.990 \\
\hline
\end{tabular}

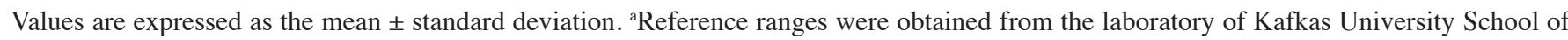
Medicine. Reference hormonal values in the early follicular phase of menstruation is presented. ${ }^{b} \mathrm{P}<0.05$, control vs. PCOS, as determined by a non-parametric Mann-Whitney U-test or t-test. PCOS, polycystic ovary syndrome; BMI, body mass index; FSH, follicle-stimulating hormone; LH, luteinizing hormone; TSH, thyroid-stimulating hormone; HDL-C, high-density-lipoprotein cholesterol; LDL-C, low-density-lipoprotein cholesterol; DHEA-S, dehydroepiandrosterone sulfate; SHBG, sex hormone-binding globulin; FAI, free androgen index; FBG, fasting blood glucose; HOMA-IR, homeostasis model assessment insulin resistance index; hs-CRP, high-sensitivity C-reactive protein.

\section{Results}

Demographic and laboratory characteristics of the study population. The clinicopathological parameters of the subjects are presented in Table I. The age, the levels of FSH and LH, and the FAI were identified to be significantly different between the patient and control groups. Furthermore, myostatin levels were detected within the normal range in the PCOS and control groups and no significant differences were identified between the PCOS $(17.52 \pm 11.2)$ and the control $(28.27 \pm 35.48)$ group $(\mathrm{P}>0.05)$.

Correlation analysis. In the control group, no significant correlations were identified between the myostatin levels and any of the other parameters. Only the LDL-C levels in the PCOS group were identified to have a significant, but negative correlation with the myostatin values (correlation coefficient, $r=-0.362 ; \mathrm{P}<0.05$; Table II). These results suggested that in
PCOS patients, a higher serum level of LDL-C was associated with a lower serum level of myostatin.

Multivariate regression analysis. Three different regression analyses were applied to the entire study sample (subjects from control and PCOS groups) (Table III). By adding and subtracting models, those models for meaningless variables were eliminated and the most meaningful regression models were identified. The model significance parameter F (F statistic/F-value) was demonstrated to be appropriate, whereas the variance inflation factor (VIF) values were far from the multicollinearity problem, and the coefficient of determination $\left(\mathrm{R}^{2}\right)$ values were determined to be $11.2 \%$ for the whole sample, $23.4 \%$ for the control group and $54.2 \%$ for the patients with PCOS. In the regression model of the entire study population, an increase in LDL-C and FBG were associated with a decrease in myostatin $(\mathrm{P}=0.008$ and $\mathrm{P}=0.036$ respectively). In the model of the PCOS group, an increase 
Table II. Correlation between myostatin levels and laboratory parameters.

\begin{tabular}{|c|c|c|c|c|c|c|}
\hline \multirow[b]{2}{*}{ Parameter } & \multicolumn{2}{|c|}{ PCOS } & \multicolumn{2}{|c|}{ Controls } & \multicolumn{2}{|c|}{ Whole population } \\
\hline & $\mathrm{r}$ & P-value & $\mathrm{r}$ & P-value & $\mathrm{r}$ & P-value \\
\hline Age (years) & -0.083 & 0.582 & -0.028 & 0.861 & -0.044 & 0.681 \\
\hline BMI $\left(\mathrm{kg} / \mathrm{m}^{2}\right)$ & 0.019 & 0.899 & -0.138 & 0.384 & -0.063 & 0.557 \\
\hline Waist circumference $(\mathrm{cm})$ & -0.234 & 0.118 & 0.067 & 0.673 & -0.108 & 0.318 \\
\hline FSH $(\mathrm{mIU} / \mathrm{ml})$ & 0.037 & 0.809 & 0.099 & 0.532 & 0.083 & 0.444 \\
\hline $\mathrm{LH}(\mathrm{mIU} / \mathrm{ml})$ & -0.147 & 0.329 & 0.117 & 0.461 & -0.045 & 0.676 \\
\hline Estradiol (pg/ml) & -0.048 & 0.752 & -0.034 & 0.831 & -0.024 & 0.822 \\
\hline Prolactin (ng/ml) & -0.198 & 0.188 & -0.014 & 0.932 & -0.066 & 0.540 \\
\hline $\mathrm{TSH}(\mu \mathrm{IU} / \mathrm{ml})$ & 0.113 & 0.453 & 0.141 & 0.372 & 0.112 & 0.297 \\
\hline HDL-C (mg/dl) & 0.094 & 0.533 & -0.007 & 0.965 & 0.051 & 0.638 \\
\hline LDL-C (mg/dl) & -0.362 & $0.018^{\mathrm{a}}$ & -0.217 & 0.148 & -0.254 & $0.016^{\mathrm{a}}$ \\
\hline Triglyceride (mg/dl) & 0.067 & 0.659 & 0.071 & 0.657 & 0.066 & 0.542 \\
\hline Total cholesterol (nmol/l) & -0.028 & 0.855 & -0.248 & 0.114 & -0.184 & 0.087 \\
\hline DHEA-S $(\mu \mathrm{g} / \mathrm{dl})$ & 0.060 & 0.693 & 0.064 & 0.689 & 0.045 & 0.680 \\
\hline Total testosterone $(\mathrm{nmol} / \mathrm{l})$ & -0.016 & 0.916 & 0.041 & 0.798 & 0.015 & 0.891 \\
\hline SHBG $(\mathrm{nmol} / \mathrm{l})$ & -0.204 & 0.175 & -0.175 & 0.268 & -0.193 & 0.071 \\
\hline FAI $(\%)$ & 0.050 & 0.743 & 0.196 & 0.214 & 0.104 & 0.335 \\
\hline $\mathrm{FBG}(\mathrm{mg} / \mathrm{dl})$ & -0.413 & 0.004 & 0.067 & 0.673 & -0.179 & 0.094 \\
\hline Insulin $(\mu \mathrm{IU} / \mathrm{ml})$ & -0.053 & 0.728 & 0.270 & 0.084 & 0.065 & 0.544 \\
\hline HOMA-IR & -0.130 & 0.390 & 0.216 & 0.169 & 0.030 & 0.783 \\
\hline hs-CRP (mg/l) & 0.051 & 0.736 & 0.053 & 0.738 & 0.058 & 0.589 \\
\hline Albumin $(\mathrm{g} / \mathrm{dl})$ & -0.273 & 0.067 & 0.050 & 0.751 & 0.008 & 0.940 \\
\hline Neutrophils $\left(\times 10^{3} / \mu 1\right)$ & -0.122 & 0.419 & -0.018 & 0.909 & -0.067 & 0.536 \\
\hline Lymphocytes $\left(\times 10^{3} / \mu 1\right)$ & 0.007 & 0.964 & -0.150 & 0.343 & -0.100 & 0.353 \\
\hline Monocytes $\left(\times 10^{3} / \mu 1\right)$ & -0.081 & 0.591 & -0.168 & 0.288 & -0.138 & 0.199 \\
\hline Platelets $\left(\times 10^{3} / \mu 1\right)$ & -0.153 & 0.311 & -0.082 & 0.604 & -0.088 & 0.416 \\
\hline
\end{tabular}

Pearson's and non-parametric Spearman correlation analysis was performed. ${ }^{\mathrm{a}} \mathrm{P}<0.05$. r, correlation coefficient; PCOS, polycystic ovary syndrome; BMI, body mass index; FSH, follicle-stimulating hormone; LH, luteinizing hormone; TSH, thyroid-stimulating hormone; HDL-C, high-density-lipoprotein cholesterol; LDL-C, low-density-lipoprotein cholesterol; DHEA-S, dehydroepiandrosterone sulfate; SHBG, sex hormone-binding globulin; FAI, free androgen index; FBG, fasting blood glucose; HOMA-IR, homeostasis model assessment insulin resistance index; hs-CRP, high-sensitivity C-reactive protein.

in LDL-C and PRL were associated with a decrease in myostatin $(\mathrm{P}=0.001$ and $\mathrm{P}=0.013$, respectively). Furthermore, a decrease in SHBG, FBG and monocytes were associated with an increase in myostatin $(\mathrm{P}=0.028, \mathrm{P}<0.001$ and $\mathrm{P}=0.026$, respectively). An increase in triglycerides was also associated with an increase in myostatin $(\mathrm{P}=0.001)$. In the model of the control group, a decrease in LDL-C was associated with an increase in myostatin $(\mathrm{P}=0.003)$ and a decrease in thyroid-stimulating hormone was associated with a decrease in myostatin $(\mathrm{P}=0.028)$.

\section{Discussion}

The size of the circulating myostatin pool regulates the overall metabolic balance between fat and muscle mass (13). Therefore, an association may exist between myostatin levels and IR, and between myostatin levels and obesity. Previous studies reporting conflicting results have indicated that changes in serum myostatin levels may be due to unknown multifactorial effects, which remain elusive (17,22-26). Although a significant age difference was identified between the groups of the present study, it was previously demonstrated that the serum myostatin levels in females did not change with age (29). The results of the present study did not indicate any significant differences in the serum myostatin levels of the patients with PCOS compared with those in the control group. This is inconsistent with the results of a similar previous study by Chen et al (20). They demonstrated that the myostatin levels were higher in patients with PCOS compared with those in female subjects without PCOS. A previous study which assessed a mouse model of obesity and diabetes (30) revealed that inflammatory cytokines, IR and physical inactivity may block myostatin synthesis and release the functions of muscular mass. Myostatin expression is not expected to increase as a result of worse metabolic profiles (31). Theoretically, by blocking the synthesis of myostatin, elevated hs-CRP and HOMA-IR may inhibit any increase in circulating myostatin levels. No significant 
Table III. Evaluation of the impact of variables on circulating myostatin using multiple linear regression analysis.

\begin{tabular}{|c|c|c|c|c|c|c|c|c|c|}
\hline \multirow[b]{2}{*}{ Group/parameter } & \multirow[b]{2}{*}{$\beta$} & \multicolumn{2}{|c|}{$95 \% \mathrm{CI}$} & \multirow[b]{2}{*}{ P-value } & \multirow[b]{2}{*}{ Tolerance } & \multirow[b]{2}{*}{ VIF } & \multirow{2}{*}{$\begin{array}{l}\text { Partial Correlation } \\
\left.\text { [Individual } \mathrm{R}^{2}(\%)\right]\end{array}$} & \multirow[b]{2}{*}{ F (P-value) } & \multirow[b]{2}{*}{$\mathrm{R}^{2}(\%)$} \\
\hline & & Lower & Upper & & & & & & \\
\hline $\begin{array}{l}\text { Whole population } \\
(\mathrm{n}=88)\end{array}$ & & & & & & & & $5.357(0.006)$ & \\
\hline Constant (intercept) & 89.836 & 44.238 & 135.434 & $<0.001^{\mathrm{a}}$ & & & & & 11.20 \\
\hline LDL-C & -0.274 & -0.475 & -0.073 & $0.008^{\mathrm{a}}$ & 0.988 & 1.012 & $-0.281(6.40)$ & & \\
\hline FBG & -0.456 & -0.881 & -0.031 & $0.036^{\mathrm{a}}$ & 0.988 & 1.012 & $-0.225(3.60)$ & & \\
\hline Controls (n=42) & & & & & & & & $5.956(0.006)$ & \\
\hline Constant (intercept) & 63.684 & 24.562 & 102.806 & $0.002^{\mathrm{a}}$ & & & & & 23.40 \\
\hline LDL-C & -0.630 & -1.038 & -0.222 & $0.003^{\mathrm{a}}$ & 0.920 & 1.087 & $-0.447(13.10)$ & & \\
\hline TSH & 12.965 & 1.514 & 24.416 & $0.028^{\mathrm{a}}$ & 0.920 & 1.087 & $0.344(4.20)$ & & \\
\hline $\operatorname{PCOS}(n=46)$ & & & & & & & & $7.694(<0.001)$ & \\
\hline Constant (intercept) & 85.397 & 61.642 & 109.153 & $<0.001^{\mathrm{a}}$ & & & & & 54.20 \\
\hline LDL-C & -0.164 & -0.258 & -0.070 & $0.001^{\mathrm{a}}$ & 0.898 & 1.113 & $-0.491(4.70)$ & & \\
\hline Prolactin & -0.597 & -1.061 & -0.133 & $0.013^{\mathrm{a}}$ & 0.919 & 1.088 & $-0.385(3.90)$ & & \\
\hline Triglyceride & 0.060 & 0.027 & 0.093 & $0.001^{\mathrm{a}}$ & 0.818 & 1.222 & $0.507(6.30)$ & & \\
\hline SHBG & -0.079 & -0.149 & -0.009 & $0.028^{\mathrm{a}}$ & 0.964 & 1.037 & $-0.343(2.70)$ & & \\
\hline FBG & -0.427 & -0.600 & -0.253 & $<0.001^{\mathrm{a}}$ & 0.906 & 1.104 & $-0.623(15.70)$ & & \\
\hline Monocytes & -21.123 & -39.553 & -2.692 & $0.026^{\mathrm{a}}$ & 0.793 & 1.261 & $-0.348(0.50)$ & & \\
\hline
\end{tabular}

${ }^{\mathrm{a}} \mathrm{P}<0.05$. $\beta$, unstandardized regression coefficient; $\mathrm{CI}$, confidence interval; VIF, variance inflation factor; F, F statistic/F-value; R2, determination coefficient; LDL-C, low-density-lipoprotein cholesterol; FBG, fasting blood glucose; TSH, thyroid-stimulating hormone; PCOS, polycystic ovary syndrome; SHBG, sex hormone-binding globulin.

correlation of HOMA-IR or hs-CRP with myostatin levels was identified in the present study.

The association between myostatin and insulin action in humans has yet to be elucidated. Previous studies have reported a positive correlation of myostatin levels with IR and with obesity. Hittel et al (23) reported a positive association between serum myostatin levels and IR, whereas Toloza et al (24) did not identify any association between the serum myostatin levels and IR. Furthermore, Camporez et al (32) observed that insulin sensitivity increased in adult mice treated with anti-myostatin, but did not change in young mice that received the same treatment. In the present study, no correlation was identified between the serum levels of myostatin and hormonal and demographic parameters. It was noteworthy that the regression analysis did not identify any association of IR with myostatin levels. A previous study on skeletal muscle in patients with PCOS revealed that insulin action was reduced, and that the activity of insulin-signaling pathways and glucose uptake were decreased (2). Therefore, reduced insulin activity in the skeleton may exert an inhibitory effect on myostatin synthesis and release.

A regression analysis performed in the present study identified the serum FBG levels as a factor causing a decrease in myostatin levels. The basic mechanisms by which increased glucose levels decrease the myostatin levels remain elusive. Han et al (31) reported that diabetic patients had lower serum myostatin levels compared with control subjects, and that serum myostatin levels were inversely correlated with metabolic syndrome parameters. Furthermore, Palsgaard et al (33) observed elevated muscle myostatin levels in diabetic patients, while Brandt et al (26) were not able to identify any significant differences in serum myostatin levels between diabetic patients and a control group. Due to these conflicting results regarding aberrant myostatin levels in diabetic patients among various studies, including the present one, it is not possible to reach any firm conclusions with this regard. Theoretically, high glucose levels are able to affect the adipose tissue ratios of diabetic patients, leading to a change in circulating myostatin levels.

In the PCOS group, increases in SHBG, LDL-C, PRL, monocytes and FBG levels were determined to be associated with a decrease in serum myostatin levels, whereas an increase in the levels of triglycerides was associated with an increase in myostatin levels. It is known that myostatin is associated with fat metabolism, in which triglycerides have a role (15).

An adequate metabolic profile has been reported to be associated with high myostatin (31). Androgen production is expected to be increased in patients with PCOS (34). Under non-physiological conditions, the association between androgens and muscle mass has remained to be properly defined (35,36). Myostatin levels were reported to increase to stop muscle growth in response to muscle development (30); therefore, myostatin may be increased in PCOS to inhibit muscle development due to the high associated androgen levels. However, the muscle capacity of the patients was not evaluated in the present study and only the BMI was measured. As the BMI in the control group was similar to that in the PCOS group, the effect of muscle mass on myostatin levels may have therefore been negligible. 
In conclusion, an improved understanding of the mechanism of action of myostatin will provide novel opportunities for understanding the pathophysiology of PCOS. The small sample size is a limitation of the present study. Detecting potential factors affecting myostatin levels may help to improve obesity, IR and ovulatory dysfunction in patients with PCOS in the future. Myostatin may be used as a biomarker to detect metabolic disorders in PCOS. Elevated or decreased serum myostatin levels in patients with PCOS may be indicative of an impaired metabolic profile. However, future studies which assess the effects of therapeutic interventions for PCOS on serum levels of myostatin are recommended.

\section{Acknowledgements}

The author thanks Dr Nilüfer Celik (Clinic of Biochemistry, Behçet Uz Children's Hospital, İzmir, Turkey) for her help with the biochemical analysis.

\section{Funding}

No funding was received.

\section{Availability of data and materials}

All data generated or analyzed during this study are included in this published article.

\section{Author's contributions}

HA was involved in the acquisition, analysis and interpretation of data for the study, drafting the work and critically revising it for important intellectual content.

\section{Ethics approval and consent to participate}

The present study was performed in accordance with the Declaration of Helsinki, and was approved by the Local Ethics Committee of Kafkas University School of Medicine (28 February 2018; no. 80576354-050-99/67). All subjects provided written informed consent to participate in the study.

\section{Patient consent for publication}

Not required.

\section{Competing interests}

The author declares he has no competing interests.

\section{References}

1. Rotterdam ESHRE/ASRM-sponsored PCOS consensus workshop group: Revised 2003 consensus on diagnostic criteria and long-term health risks related to polycystic ovary syndrome (PCOS). Hum Reprod 19: 41-47, 2004.

2. Morin-Papunen LC, Vauhkonen I, Koivunen RM, Ruokonen A and Tapanainen JS: Insulin sensitivity, insulin secretion, and metabolic and hormonal parameters in healthy women and women with polycystic ovarian syndrome. Hum Reprod 15: 1266-1274, 2000.

3. Ehrmann DA and Rychlik D: Pharmacologic treatment of polycystic ovary syndrome. Semin Reprod Med 21: 277-283, 2003.
4. Torchen LC: Cardiometabolic risk in PCOS: More than a reproductive disorder. Curr Diab Rep 17: 137, 2017.

5. Bortoluzzi S, Scannapieco P, Cestaro A, Danieli GA and Schiaffino S: Computational reconstruction of the human skeletal muscle secretome. Proteins 62: 776-792, 2006.

6. Yoon JH, Yea K, Kim J, Choi YS, Park S, Lee H, Lee CS, Suh PG and Ryu SH: Comparative proteomic analysis of the insulin-induced L6 myotube secretome. Proteomics 9: 51-60, 2009.

7. Henningsen J, Rigbolt KT, Blagoev B, Pedersen BK and Kratchmarova I: Dynamics of the skeletal muscle secretome during myoblast differentiation. Mol Cell Proteomics 9: 2482-2496, 2010.

8. McPherron AC, Lawler AM and Lee SJ: Regulation of skeletal muscle mass in mice by a new TGF-beta superfamily member. Nature 387: 83-90, 1997.

9. Sharma M, Kambadur R, Matthews KG, Somers WG, Devlin GP, Conaglen JV, Fowke PJ and Bass JJ: Myostatin, a transforming growth factor-beta superfamily member, is expressed in heart muscle and is upregulated in cardiomyocytes after infarct. J Cell Physiol 180: 1-9, 1999.

10. Amirouche A, Durieux AC, Banzet S, Koulmann N, Bonnefoy R, Mouret C, Bigard X, Peinnequin A and Freyssenet D: Down-regulation of $\mathrm{Akt} / \mathrm{mammalian}$ target of rapamycin signaling pathway in response to myostatin overexpression in skeletal muscle. Endocrinology 150: 286-294, 2008.

11. Durieux AC, Amirouche A, Banzet S, Koulmann N, Bonnefoy R, Pasdeloup M, Mouret C, Bigard X, Peinnequin A and Freyssenet D: Ectopic expression of myostatin induces atrophy of adult skeletal muscle by decreasing muscle gene expression. Endocrinology 148: 3140-3147, 2007.

12. Lee SJ, Reed LA, Davies MV, Girgenrath S, Goad ME, Tomkinson KN, Wright JF, Barker J, Ehrmantraut G, Holmstrom J, et al: Regulation of muscle growth by multiple ligands signaling through activin type II receptors. Proc Natl Acad Sci USA 102: 18117-18122, 2005.

13. Lee SJ: Extracellular regulation of myostatin: A molecular rheostat for muscle mass. Immunol Endocr Metab Agents Med Chem 10: 183-194, 2010.

14. Park JJ, Berggren JR, Hulver MW, Houmard JA and Hoffman EP: GRB14, GPD1, and GDF8 as potential network collaborators in weight loss-induced improvements in insulin action in human skeletal muscle. Physiol Genomics 27: 114-121, 2006.

15. Argilés JM, Orpí M, Busquets S and López-Soriano FJ: Myostatin: More than just a regulator of muscle mass. Drug Discov Today 17: 702-709, 2012.

16. Taylor WE, Bhasin S, Artaza J, Byhower F, Azam M, Willard DH Jr, Kull FC Jr and Gonzalez-Cadavid N: Myostatin inhibits cell proliferation and protein synthesis in $\mathrm{C} 2 \mathrm{C} 12$ muscle cells. Am J Physiol Endocrinol Metab 280: E221-E228, 2001

17. Hittel DS, Berggren JR, Shearer J, Boyle K and Houmard JA: Increased secretion and expression of myostatin in skeletal muscle from extremely obese women. Diabetes 58: 30-38, 2009.

18. Islam MS, Catherino WH, Protic O, Janjusevic M, Gray PC, Giannubilo SR, Ciavattini A, Lamanna P, Tranquilli AL, Petraglia F, et al: Role of activin-A and myostatin and their signaling pathway in human myometrial and leiomyoma cell function. J Clin Endocrinol Metab 99: E775-E785, 2014.

19. Guo J, Tian T, Lu D, Xia G, Wang H and Dong M: Alterations of maternal serum and placental follistatin-like 3 and myostatin in pre-eclampsia. J Obstet Gynaecol Res 38: 988-996, 2012.

20. Chen MJ, Han DS, Yang JH, Yang YS, Ho HN and Yang WS: Myostatin and its association with abdominal obesity, androgen and follistatin levels in women with polycystic ovary syndrome. Hum Reprod 27: 2476-2483, 2012.

21. McMahon CD, Popovic L, Jeanplong F, Oldham JM, Kirk SP, Osepchook CC, Wong KW, Sharma M, Kambadur R and Bass JJ: Sexual dimorphism is associated with decreased expression of processed myostatin in males. Am J Physiol Endocrinol Metab 284: E377-E381, 2003.

22. Bonala S, Lokireddy S, McFarlane C, Patnam S, Sharma M and Kambadur R: Myostatin induces insulin resistance via Casitas B-lineage lymphoma $\mathrm{b}$ (Cblb)-mediated degradation of insulin receptor substrate 1 (IRS1) protein in response to high calorie diet intake. J Biol Chem 289: 7654-7670, 2014.

23. Hittel DS, Axelson M, Sarna N, Shearer J, Huffman KM and Kraus WE: Myostatin decreases with aerobic exercise and associates with insulin resistance. Med Sci Sports Exerc 42: 2023-2029, 2010 
24. Toloza FJK, Mantilla-Rivas JO, Pérez-Matos MC, Ricardo-Silgado ML, Morales-Alvarez MC, Pinzón-Cortés JA, Pérez-Mayorga M, Arévalo-Garcia ML, Tolosa-González G and Mendivil CO: Plasma levels of myonectin but not myostatin or FGF-21 are associated with insulin resistance in adult humans without diabetes mellitus. Front Endocrinol (Lausanne) 9: 5, 2018.

25. Hjorth M, Pourteymour S, Görgens SW, Langleite TM, Lee S, Holen T, Gulseth HL, Birkeland KI, Jensen J, Drevon CA and Norheim F: Myostatin in relation to physical activity and dysglycaemia and its effect on energy metabolism in human skeletal muscle cells. Acta Physiol (Oxf) 217: 45-60, 2016.

26. Brandt C, Nielsen AR, Fischer CP, Hansen J, Pedersen BK and Plomgaard P: Plasma and muscle myostatin in relation to type 2 diabetes. PLoS One 7: e37236, 2012.

27. Ferriman D and Gallwey JD: Clinical assessment of body hair growth in women. J Clin Endocrinol Metab 21: 1440-1447, 1961.

28. Matthews DR, Hosker JP, Rudenski AS, Naylor BA, Treacher DF and Turner RC: Homeostasis model assessment: Insulin resistance and $\beta$-cell function from fasting plasma glucose and insulin concentrations in man. Diabetologia 28: 412-419, 1985.

29. Schafer MJ, Atkinson EJ, Vanderboom PM, Kotajarvi B, White TA, Moore MM, Bruce CJ, Greason KL, Suri RM, Khosla S, et al: Quantification of GDF11 and myostatin in human aging and cardiovascular disease. Cell Metab 23: 1207-1215, 2016.

30. Nguyen MH, Cheng $M$ and Koh TJ: Impaired muscle regeneration in ob/ob and db/db mice. ScientificWorldJournal 11: 1525-1535, 2011.

31. Han DS, Chu-Su Y, Chiang CK, Tseng FY, Tseng PH, Chen CL, Wu KD and Yang WS: Serum myostatin is reduced in individuals with metabolic syndrome. PLoS One 9: e108230, 2014.
32. Camporez JPG, Petersen MC, Abudukadier A, Moreira GV, Jurczak MJ, Friedman G, Haqq CM, Petersen KF and Shulman GI: Anti-myostatin antibody increases muscle mass and strength and improves insulin sensitivity in old mice. Proc Nat Acad Sci USA 113: 2212-2217, 2016.

33. Palsgaard J, Brøns C, Friedrichsen M, Dominguez H, Jensen M, Storgaard H, Spohr C, Torp-Pedersen C, Borup R, De Meyts P and Vaag A: Gene expression in skeletal muscle biopsies from people with type 2 diabetes and relatives: Differential regulation of insulin signaling pathways. PLoS One 4: e6575, 2009.

34. Goodman NF, Cobin RH, Futterweit W, Glueck JS, Legro RS and Carmina E; American Association of ClinicalEndocrinologists (AACE); American College of Endocrinology (ACE); Androgen Excess and PCOS Society: American association of clinical endocrinologists, American college of endocrinology, and androgen excess and PCOS society disease state clinical review: Guide to the best practices in the evaluation and treatment of polycystic ovary syndrome-part 2. Endocr Pract 21: 1415-1426, 2015.

35. Helene HDN: Androgens and the molecular regulation of skeletal muscle mass. Doctoral dissertation, Gent University, Gent, Belgium, 2014. https://biblio.ugent. be/publication/4411710/file/4411749.

36. Kogure GS, Miranda-Furtado CL, Silva RC, Melo AS, Ferriani RA, De Sá MF and Dos Reis RM: Resistance exercise impacts lean muscle mass in women with polycystic ovary syndrome. Med Sci Sports Exerc 48: 589-598, 2016.

(c) (i) This work is licensed under a Creative Commons Attribution 4.0 International (CC BY 4.0) License. 